\title{
Analisis Pendapatan Masyarakat Desa untuk Kelestarian Hutan Lindung (Studi Hutan Desa Pattaneteang Kabupaten Bantaeng)
}

\author{
Sukardi ${ }^{1}$, \\ ${ }^{1}$ Mahasiswa Program Studi IImu Lingkungan Sekolah IImu Lingkungan Universitas Indonesia \\ *E-mail: deekaforest@gmail.com
}

\begin{abstract}
Average income of Pattaneteang rural community aren't ideal. This condition is resulting land utilization of rural forest in preserved forest area to increase their income and threats the forest sustainability in both rural community. Therefore, it is necessary to note the influence from both rural community income either from inside nor outside the rural forest on community management land as one of the indicators of to preserved forest sustainability. The quantitative approach used in this research is used to analyze field and secondary data as comparative data. From the research it is know, the biggest Pattaneteang income is gain by using land outside the rural forest worth Rp. 14.060.500/Family/Year, while using land inside rural forest only worth Rp. 3.338.000/Family/Year. This income affects the community management land as an indicator of the condition of preservation of protected forest areas in both of the rural.
\end{abstract}

Keywords: rural community income; rural forest; income from outside rural forest; income from inside rural forest; sustainability of preserved forest area

DOI: 10.24259/jhm.v9i1.2047

\section{PENDAHULUAN}

Masyarakat sekitar hutan memiliki posisi dilematis dalam kaitannya dengan hutan. Pada satu sisi mereka adalah masyarakat yang paling berperan dalam konteks pelestarian hutan. Pada sisi lain, kondisi mereka rata-rata miskin dan sangat membutuhkan penopang untuk memenuhi beragam kebutuhan hidupnya. Hutan adalah sumber daya ekonomi yang sangat melimpah bagi pemenuhan kebutuhan masyarakat sekitar hutan. Kondisi tersebut menjadi berkah bagi masyarakat untuk memanfaatkan sumber daya hutan yang ada untuk memenuhi kebutuhan hidup (Al Hasan dan Yumantoko, 2012).

Desa Pattaneteang adalah salah satu desa yang sebagian wilayah administrasinya berada pada kawasan hutan lindung. Kondisi kawasan hutan lindung di Desa Pattaneteang sebagian telah dimanfaatkan lahannya untuk pertanian oleh masyarakat dengan tanaman kopi. Pemanfaatan lahan hutan oleh masyarakat Desa Pattaneteang adalah salah satu sumber pendapatan mereka.

Pendapatan rata-rata masyarakat Desa Pattaneteang dan masyarakat Desa Campaga sebesar Rp. 5.446.500/KK/tahun atau sebesar $73,6 \%$ dari kebutuhan yang mereka anggap ideal sebesar Rp. $7.400 .800 / \mathrm{KK} /$ tahun (diolah dari Supratman \& Sahide, 2013). Pendapatan ideal tersebut adalah pendapatan minimal yang harus dipenuhi masyarakat Desa Pattaneteang. Kondisi ini menjadi salah satu pemicu masyarakat Desa Pattaneteang memanfaatkan lahan di kawasan hutan di desa mereka untuk menambah pendapatan.

Pemanfaatan lahan hutan di Desa Pattaneteang berpotensi konflik tinggi karena masyarakat tidak memiliki izin pemanfaatan dari pemerintah. Berdasarkan Surat Keputusan Menteri Kehutanan Nomor SK.434/Menhut-II/2009 tanggal 23 Juli September 2009 tentang Peta Kawasan Hutan dan Konservasi Provinsi Sulawesi Selatan, hutan yang dimanfaatkan lahannya di dua desa memiliki fungsi hutan lindung. Fungsi lindung dimaksud tidak membolehkan penebangan pohon karena akan mengganggu sistem tata air di sekitar hutan. Apabila terjadi pembiaran dikhawatirkan perambahan hutan akan terus bertambah, meskipun masyarakat hutan desa memiliki kearifan lokal dalam menjaga hutan. Kondisi ini akan berakibat langsung pada penutupan lahan hutan sebagai salah satu indikator kelestarian hutan.

Program Hutan Desa ditujukan untuk memberi solusi agar masyarakat desa dapat memanfaatkan hutan secara legal. Sebelum program hutan desa, masyarakat desa dianggap sebagai 
perambah hutan oleh pemerintah, sementara masyarakat menganggap memanfaatkan lahan hutan adalah kebiasaan yang sudah berlangsung lama sehingga pemerintah tidak berhak melarang mereka. Oleh karena itu, program Hutan Desa diberikan sebagai solusi konflik pemanfaatan lahan hutan. Program Hutan Desa memberikan izin hak pengelolaan kepada Badan Usaha Milik Desa di kedua Desa selama 35 tahun seluas $\pm 339 \mathrm{Ha}$ di Desa Pattaneteang. Izin tersebut diberikan sejak tahun 2009 dan akan berakhir pada tahun 2044 dan izin tersebut dapat diperpanjang kembali. Status kawasan hutan yang masyarakat garap atau manfaatkan tetap sebagai hutan lindung, sementara lahan yang sudah terlanjur ditanami kopi di Desa Pattaneteang masih dipertahankan dengan melakukan penanaman pohon keras di sela-sela tanaman kopi.

Pendapatan masyarakat Desa Pattaneteang melalui program Hutan Desa diharapkan dapat meningkat sehingga penutupan lahan dipertahankan atau terjaga kawasan hutan lindungnya. Penelitian ini dilakukan untuk mendapatkan pembelajaran dan bahan pertimbangan berbagai pihak terutama masyarakat desa lain yang akan mengelola hutan desa, akademisi sebagai bahan acuan untuk penelitian lanjutan, fasilitator maupun pemerintah untuk evaluasi program.

Rumusan masalah penelitian ini adalah pendapatan masyarakat Desa Pattaneteang dari pertanian di luar Hutan Desa masih lebih rendah dari pendapatan minimal masyarakat di Kabupaten Bantaeng. Pertanian di luar Hutan Desa berasal dari produksi kopi dan cengkeh. Kondisi tesebut mengakibatkan masyarakat Desa Pattaneteang melakukan pemanfaatan pertanian dan pemungutan hasil hutan di dalam Hutan Desa yang berada di wilayah mereka sebagai salah satu sumber pendapatan. Pertanian dari dalam Hutan Desa berasal dari produksi kopi dan pemungutan Hasil Hutan Bukan Kayu. Pemanfaatan lahan Hutan Desa sebagai sumber pendapatan akan mengancam kelestarian kawasan hutan lindung apabila tidak dikelola dengan baik. Karena itu, penelitian ini dilakukan dengan tujuan menganalisis pendapatan masyarakat Hutan Desa Pattaneteang dan menganalisis pengaruh pendapatan pada kelestarian Hutan Desa Pattaneteang.

\section{METODOLOGI PENELITIAN}

\subsection{Tempat dan Waktu}

Riset dilakukan pada bulan September 2015 sampai bulan Januari 2016. Tempat penelitian di Desa Pattaneteang Kecamatan Tompobulu, Kabupaten Bantaeng Provinsi Sulawesi Selatan.

\subsection{Bahan dan Alat Riset}

\subsubsection{Survei Pendahuluan}

Survei pendahuluan dilakukan dengan menggunakan data-data dari Direktorat Penyiapan Kawasan Perhutanan Sosial mengenai lokasi Hutan Desa yang hak pengelolaannya telah berlangsung lebih dari 5 tahun. Lokasi yang dipilih adalah Desa Pattaneteang yang telah mendapatkan Hak Pengelolaan dari Gubernur Sulawesi Selatan Nomor: 3805/XI/TH/2010 tanggal 26 November 2010. Setelah mendapatkan lokasi yang diinginkan dilakukan kajian pustaka dari berbagai sumber terkait Hutan Desa Pattaneteang.

\subsection{Populasi dan Sampel}

\subsubsection{Populasi}

Populasi dalam penelitian ini adalah masyarakat Desa Pattaneteang yaitu penduduk desa yang diwakili oleh kepala keluarga. Jumlah kepala keluarga berdasarkan data BPS Kabupaten Bantaeng Tahun 2015 di Desa Pattaneteang 466 KK. 


\subsubsection{Sampel}

Pengambilan sampel dalam riset ini dilakukan secara acak tanpa memperhatikan strata yang ada (simple random sampling). Jumlah sampel yang diambil dalam riset ini sebanyak 60 sampel dengan kuesioner masing-masing masyarakat Desa Pattaneteang sebanyak 30 sampel dan masyarakat Desa Campaga sebanyak 30 sampel. Penentuan sampel tersebut sesuai dengan pendapat Rescoe dalam Sugiyono (2014), bahwa ukuran sampel penelitian yang layak sebanyak 30- 500 sampel. Hal tersebut dipertegas oleh Cohen, et.al, (2007) bahwa semakin besar sampel dari besarnya populasi yang ada adalah semakin baik, akan tetapi ada jumlah batas minimal yang harus diambil oleh peneliti yaitu sebanyak 30 sampel.

\subsection{Data Riset}

\subsubsection{Jenis Data dan Metode Pengumpulan Data}

Data yang dikumpulkan terdiri dari data primer dan data sekunder. Data primer dan data sekunder diperoleh melalui observasi, wawancara, Kuesioner dan dokumentasi. Data riset, instrumen pengumpulan/ pengukuran, dan metode analisis yang diperlukan dalam riset ini sebagaimana ditampilkan dalam Tabel 1.

Tabel 1. Matriks Data Riset

\begin{tabular}{lllll}
\hline No. & \multicolumn{1}{c}{ Data Riset } & \multicolumn{1}{c}{$\begin{array}{c}\text { Instrumen } \\
\text { Pengumpulan/ } \\
\text { Pengukuran }\end{array}$} & \multicolumn{1}{c}{ Pengolahan } & Metode Analisis \\
\hline 1. & Produksi Kopi dan Cengkeh & Kuesioner & $\begin{array}{l}\text { Menggunakan Rumus } \\
\text { Produktivitas }\end{array}$ & Kuantitatif \\
\hline 2. & Produksi Kopi & Kuesioner & $\begin{array}{l}\text { Menggunakan Rumus } \\
\text { Produktivitas }\end{array}$ & Kuantitatif \\
\hline 3. & Pendapatan & Kuesioner & $\begin{array}{l}\text { Menggunakan Rumus } \\
\text { Pendapatan }\end{array}$ & Kuantitatif \\
\hline
\end{tabular}

\subsubsection{Pengolahan Data}

Pengolahan data dalam riset dilakukan melalui beberapa tahapan. Data yang sudah terkumpul dilakukan kodefikasi berdasarkan variabel riset yang telah ditentukan sebelumnya. Data-data diolah sesuai dengan rumus yang digunakan dalam riset ini, kemudian dilakukan tabulasi data dengan memasukkan hasil pengolahan data-data kedalam tabel.

Data Produksi kopi dan cengkeh adalah produk pertanian dari luar hutan desa didapatkan dari jumlah produksi kopi dan cengkeh, masing-masing responden. Hasil produksi kopi dan cengkeh masingmasing responden dijumlahkan dan ditabulasikan kemudian dirata-ratakan untuk mengetahui produksi rata-rata yang dihasilkan dari pertanian kopi, cengkeh, masyarakat Desa Pattaneteang. Hasil pertanian kopi berdasarkan hasil kuesoner diukur dengan satuan liter sedangkan cengkeh diukur dengan satuan kilogram.

Data Pendapatan adalah hasil penjualan dari produksi pertanian dari luar dan dari dalam hutan desa serta penjualan dari hasil hutan bukan kayu dari dalam hutan desa. Hasil penjualan masing-masing produk dijumlahkan kemudian dirata-ratakan untuk mengetahui pendapatan total masing-masing responden.

Hasil penjualan komoditas yang dihitung adalah produk kopi, cengkeh, kakao, madu dan buah pangi. Untuk menghitung besarnya pendapatan masyarakat Desa Pattaneteang dari hasil penjualan produk-produk tersebut, dihitung dengan rumus dasar berikut: 
Keterangan :

$\mathrm{TR}=$ Pendapatan $(\mathrm{Rp})$

$Y=$ Jumlah produksi $(\mathrm{kg})$

Py = Harga jual produk (Rp/kg)

Sumber: Soekartawi, 2006

Hubungan (reabilitas) dan regresi sederhana antara pendapatan dan lahan kelola masyarakat Hutan Desa akan dianalisis secara statitistik dengan menggunakan metode pengolahan data memanfaatkan software IBM SPSS Statistic 24. Untuk mengetahui hubungan antar variabel dilakukan uji reabilitas dengan rumus:

$$
r=\frac{N(\Sigma X Y)-(\Sigma X \Sigma Y)}{\sqrt{\left[( N \Sigma X ^ { 2 } - ( \Sigma X ) ^ { 2 } ) \left(N \Sigma Y^{2}-\right.\right.}} \frac{(\Sigma Y)^{2}}{}
$$

Keterangan:

$$
\begin{array}{ll}
\mathrm{r} & \text { : nilai korelasi } \\
\mathrm{N} & \text { : jumlah responden/sampel } \\
\mathrm{X} & \text { : skor pernyataan } \mathrm{ke}-\mathrm{i} \\
\mathrm{Y} & \text { : skor total }
\end{array}
$$

Untuk mengetahui pengaruh pendapatan pada Lahan kelola masyarakat Hutan Desa, dilakukan analisis regresi sederhana dengan rumus:

$Y=a+b X \ldots \ldots .$. Rumus 3.10. Regresi Sederhana

Keterangan:

Y $\quad$ : variabel terikat (dependent); Lahan kelola masyarakat Hutan Desa

$\mathrm{X} \quad$ : variabel bebas (independent); Pendapatan masyarakat Hutan Desa

A : nilai konstanta

b : nilai koefisien regresi

Sumber: Sugiyono, 2009

\subsubsection{Tahapan Pelaksanaan/Rancangan Penelitian}

Pertanian dari luar Hutan Desa yang menghasilkan produksi kopi, cengkeh dan kakao yang jadi sumber pendapatan masyarakat Desa Pattaneteang dan Desa Campaga masih lebih rendah dari pendapatan minimal masyarakat di kedua desa. Pertanian dari dalam Hutan Desa menghasilkan produksi kopi dan pemungutan hasil hutan bukan kayu menghasilkan produksi madu dan buah pangi menambah pendapatan masyarakat desa, namun pertanian dari dalam Hutan Desa cenderung mengganggu kelestarian Hutan Desa yang berada pada kawasan hutan lindung jika tidak diimbangi pengelolaan yang tepat. Agar kelestarian Hutan Desa dapat terjaga maka pendapatan pertanian dari luar Hutan Desa dan pemungutan hasil hutan bukan kayu dari dalam Hutan Desa perlu ditingkatkan. 


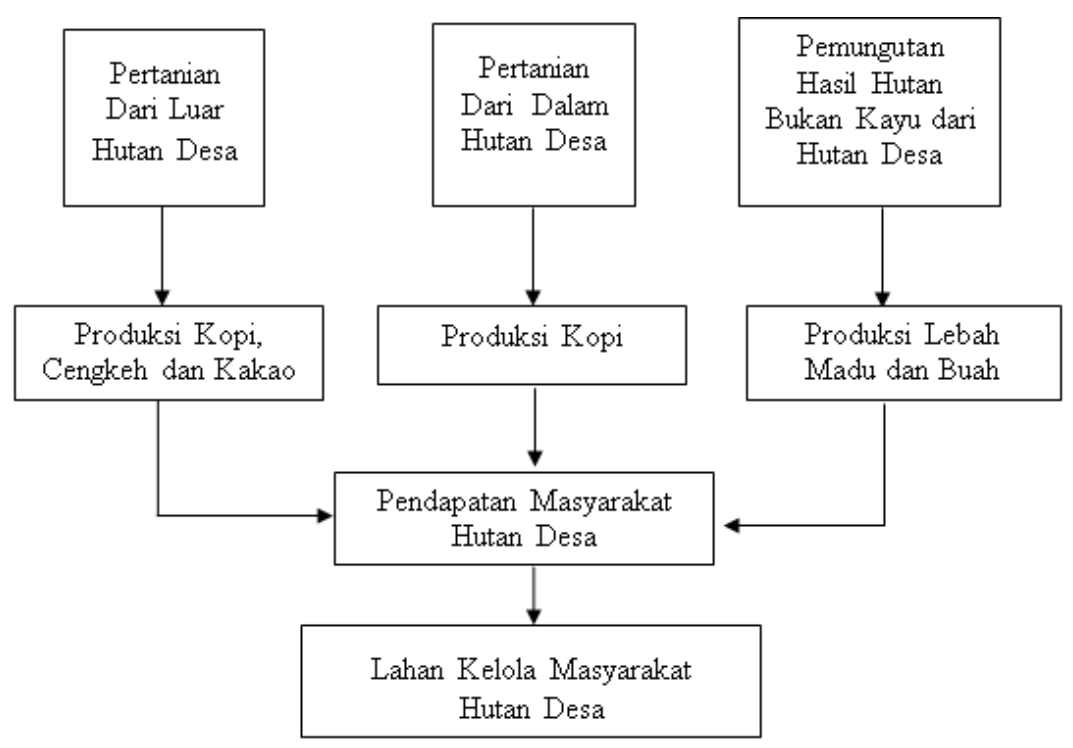

Gambar 1. Rancangan Penelitian

\subsection{Analisa Data}

Analisis data pada riset ini akan dilakukan setelah mengolah data menjadi informasi, sehingga karakteristik atau sifat-sifat data tersebut dapat dipahami dan bermanfaat untuk menjawab masalahmasalah yang berkaitan dengan kegiatan riset. Teknik analisis data dalam riset ini didasarkan pada informasi yang terkumpul dari masing-masing variabel penelitian untuk menjawab pertanyaan penelitian. Adapun analisis data yang dilakukan dalam riset ini adalah:

\subsubsection{Analisis Pendapatan Masyarakat Desa Desa Pattaneteang}

Informasi pendapatan dianalisis dari pengolahan data hasil penjualan produksi kopi dan cengkeh dari luar hutan desa, produksi kopi dari dalam hutan desa dan produksi hasil hutan bukan kayu dari dalam hutan desa. Informasi didapatkan dari hasil penjualan komoditas yang diusahakan dari luar dan dari dalam Hutan Desa sebagai gambaran besarnya pendapatan Masyarakat Desa. Jumlah pendapatan dari luar Hutan Desa akan diketahui lebih besar atau lebih kecil dari jumlah pendapatan dari dalam Hutan Desa sehingga kontribusi masing-masing pendapatan dapat diketahui.

\subsubsection{Analisis Pengaruh Pendapatan Masyarakat pada Kelestarian Hutan Desa Pattaneteang}

Informasi Pengaruh Pendapatan pada Kelestarian Hutan Desa Pattaneteang dan didapatkan dari rata-rata pendapatan dan luas areal kelola Masyarakat Desa dari luar dari dalam Hutan Desa. Informasi yang didapatkan dari model statistik regresi sederhana akan memberi gambaran bahwa semakin tinggi pendapatan akan mempengaruhi luas kelola lahan baik dari luar dan dari dalam Hutan Desa.

\section{HASIL DAN PEMBAHASAN}

\subsection{Analisis Pendapatan Masyarakat Desa Pattaneteang}

Pendapatan masyarakat Desa Pattaneteang dapat diklasifikasikan menjadi dua yaitu Pendapatan dari Pertanian Luar Hutan Desa, Pendapatan dari Pertanian dalam Hutan Desa Pattaneteang. Untuk Pendapatan dari Pemungutan Hasil Hutan Bukan Kayu dari dalam Hutan Desa 
Pattaneteang tidak dihitung karena dari 30 sampel tidak ada data masyarakat yang melakukan Pemungutan Hasil Hutan Bukan Kayu

\subsubsection{Pendapatan dari Pertanian Luar Hutan Desa}

Pendapatan masyarakat Hutan Desa Pattaneteang dari luar Hutan Desa didapatkan dari hasil penjualan produk pertanian Kopi dan Cengkeh. Rumus dasar yang digunakan adalah Rumus Pendapatan yaitu $T R=Y$ x Py dimana TR adalah Pendapatan, $Y$ adalah Jumlah Produksi dan Py adalah Harga Jual. Rumus tersebut diturunkan untuk masing-masing Pendapatan yaitu Pendapatan Kopi dengan rumus TRK $=$ YK $x$ PyK dimana TRK adalah Pendapatan Kopi, YK adalah Jumlah Produksi Kopi dan Py adalah Harga Jual Kopi. Untuk Pendapatan Cengkeh dengan rumus TRC $=Y C \times$ PyC dimana TRC adalah Pendapatan Cengkeh, YC adalah Jumlah Produksi Cengkeh dan Py adalah Harga Jual Cengkeh. Data hasil produksi yang digunakan adalah produksi rata-rata dari hasil pertanian Kopi dan hasil pertanian Cengkeh.

Produksi rata-rata pertanian Kopi yang diambil dari 30 sampel masyarakat Hutan Desa Pattaneteang adalah 519 liter/KK/tahun atau $291 \mathrm{~kg} / \mathrm{KK} / \mathrm{tahun}$. Masyarakat menjual Kopi ke pedagang pengumpul sebesar Rp. 15.000/liter sehingga dapat diketahui pendapatan rata-rata masyarakat Hutan Desa Pattaneteang dari produksi kopi sebesar Rp. 7.780.500/KK/tahun.

Untuk tanaman Cengkeh, produksi rata-rata pertanian Cengkeh yang diambil dari 30 sampel hanya ada 20 sampel masyarakat Hutan Desa Pattaneteang yang mengusahakan Cengkeh sebesar 79 $\mathrm{kg} / \mathrm{KK} / \mathrm{tahun}$. Harga jual Cengkeh di pedagang pengumpul sebesar Rp. 120.000/kg sehingga dapat diketahui pendapatan rata-rata masyarakat Hutan Desa Pattaneteang dari produksi Cengkeh sebesar Rp. 6.280.000/ KK/ tahun.

Pendapatan total masyarakat Hutan Desa Pattaneteang dari pertanian luar hutan desa disajikan pada Tabel 2.

Tabel 2. Pendapatan Total Masyarakat Hutan Desa Pattaneteang Dari Luar Hutan Desa

\begin{tabular}{llcrrc}
\hline No. & $\begin{array}{c}\text { Jenis } \\
\text { Kegiatan }\end{array}$ & $\begin{array}{c}\text { Produksi Rata-rata } \\
\text { (KK/tahun) }\end{array}$ & $\begin{array}{c}\text { Harga Jual (Rp/liter } \\
\text { atau Rp/kg) }\end{array}$ & $\begin{array}{r}\text { Total Pendapatan } \\
\text { (Rp/KK/tahun) }\end{array}$ & Persentase (\%) \\
\hline 1. & $\begin{array}{l}\text { Tanaman } \\
\text { Kopi }\end{array}$ & 519 liter & 15.000 & 7.780 .500 & 55 \\
\hline 2. & $\begin{array}{l}\text { Tanaman } \\
\text { Cengkeh }\end{array}$ & $79 \mathrm{~kg}$ & 120.000 & 6.280 .000 & 45 \\
\hline & Total & & 14.060 .500 & 100 \\
\hline
\end{tabular}

Sumber: Hasil pengolahan data kuesioner, 2016.

Berdasarkan data pada Tabel 2, diketahui total pendapatan masyarakat Hutan Desa Pattaneteang dari pertanian luar Hutan Desa sebesar Rp. 14.060.500/KK/tahun. Pendapatan masyarakat dari tanaman cengkeh lebih besar dari tanaman kopi, karena harga cengkeh lebih mahal dari harga kopi. Pendapatan adalah pendapatan gabungan dari pendapatan Kopi dan Pendapatan Cengkeh. Apabila dibandingan dengan pendapatan minimal masyarakat di Kabupaten Bantaeng terjadi lonjakan pendapatan yang sangat besar yaitu sebesar $53 \%$.

Perbandingan pendapatan yang diterima masyarakat Hutan Desa Pattaneteang dari pertanian luar Hutan Desa Pattaneteang. Pendapatan dari tanaman cengkeh sebesar $55 \%$ lebih besar dari tanaman kopi sebesar $45 \%$. Masing-masing pendapatan apabila dibandingkan dengan pendapatan minimal masyarakat di Kabupaten Bantaeng dimana pendapatan dari Kopi sebesar Rp. 7.780.500/ KK/tahun dan Rp. 6.280.000/KK/tahun masih lebih besar dari pendapatan minimal masyarakat di Kabupaten Bantaeng sebesar Rp. 7.400.800/KK/ tahun.

Besarnya perbedaan pendapatan tersebut disebabkan oleh beberapa faktor yaitu hasil produksi Kopi masyarakat di Kabupaten Bantaeng umumnya menjual dengan sistem ijon, dimana kopi yang belum dipetik sudah dijual kepada tengkulak dengan harga jauh dari harga pasar. Selain itu, ada dua tipe 
pemanenan kopi di Kabupaten Bantaeng yang juga dilakukan oleh masyarakat Hutan Desa Pattaneteang. Perbedaan kedua tipe pemanenan kopi ini adalah warna buah ketika panen. Pada panen hijau, biji kopi dipanen saat masih berwana hijau, sedangkan panen merah dilakukan dengan memanen biji kopi yang telah berwarna merah. Dulu sistem ijon dan panen hijau banyak dilakukan oleh masyarakat Hutan Desa Pattaneteang meskipun harga hanya Rp. 4.000 - Rp. 6.500 karena lebih cepat mendapatkan hasil.

Pola pemasaran dengan sistem ijon tersebut sesuai dengan hasil penelitian yang dilakukan oleh Listyati D., dan Hasibuan AM., 2012 yang menyatakan bahwa sistem ijon tidak menguntungkan bagi petani karena petani memperoleh harga yang sangat rendah. Pada sistem ijon yang berperanadalah tengkulak, pedagang pengumpul di kecamatan/kabupaten dan pengumpul besar. Pengumpul besar oleh masyarakat seringkali disebut dengan tauke, yang umumnya adalah perusahaan besar eksportir kopi yang berada di kota. Tengkulak menggunakan sistem ijon dalam transaksi, misalnya untuk kopi yang masih berbunga dibeli dengan harga tertentu, setelah panen baru kemudian di jual ke pengumpul.

Fluktuasi harga Cengkeh juga menjadi salah satu faktor tingginya perbedaan pendapatan masyarakat Hutan Desa Pattaneteang dengan pendapatan minimal masyarakat di Kabupaten Bantaeng. Fluktuasi harga Cengkeh berdasarkan data dari Kementerian Pertanian 2014 bahwa harga Cengkeh tertinggi pada tahun 2001 dengan harga Rp.51.223/kg atau harga pada tahun 2015 sekita Rp. 146.558/ $\mathrm{kg}$ berdasarkan hasil perhitungan inflasi yang terjadi. Hal tersebut berarti harga tersebut masih lebih tinggi dari harga jual Cengkeh saat data diambil sebesar Rp.120.000/kg.

\subsubsection{Pendapatan dari Pertanian dalam Hutan Desa}

Pendapatan masyarakat Hutan Desa Pattaneteang dari dalam Hutan Desa didapatkan dari hasil penjualan produk pertanian Kopi. Rumus dasar yang digunakan adalah Rumus Pendapatan yaitu $T R=Y x$ Py dimana TR adalah Pendapatan, $Y$ adalah Jumlah Produksi dan Py adalah Harga Jual. Rumus tersebut diturunkan untuk Pendapatan Kopi dengan rumus TRK = YK x PyK dimana TRK adalah Pendapatan Kopi, YK adalah Jumlah Produksi Kopi dan Py adalah Harga Jual Kopi.

Produksi rata-rata pertanian Kopi dari dalam Hutan Desa yang diambil dari 30 sampel masyarakat Hutan Desa Pattaneteang adalah 223 liter/KK/tahun atau 124,8 kg/KK/tahun. Masyarakat menjual Kopi ke pedagang pengumpul sebesarRp. 15.000/liter sehingga dapat diketahui pendapatan rata-rata masyarakat Hutan Desa Pattaneteang dari produksi kopi sebesar Rp. 3.338.000/ KK/tahun. Pendapatan total masyarakat Hutan Desa Pattaneteang dari pertanian dari dalam hutan desa disajikan pada Tabel 3 Tabel 3. Pendapatan Total Masyarakat Hutan Desa Pattaneteang Dari Dalam Hutan Desa.

\begin{tabular}{ccccc}
\hline No. & Jenis Pendapatan & $\begin{array}{c}\text { Produksi Rata-rata (literl } \\
\text { KK/tahun) }\end{array}$ & Harga Jual & $\begin{array}{c}\text { Total Pendapatan } \\
\text { (Rp/KK/tahun) }\end{array}$ \\
\hline 1. & Pertanian Kopi & 124,8 & Rp.15.000/ liter & 3.338 .000 \\
\hline & & Total & & 3.338 .000
\end{tabular}

Sumber: Hasil pengolahan data kuesioner, 2016.

Berdasarkan data dari Tabel 4.12, diketahui total pendapatan masyarakat Hutan Desa Pattaneteang dari pertanian dalam Hutan Desa sebesar Rp. 3.338.000/ KK/tahun. Pendapatan tersebut masih lebih kecil apabila dibandingkan dengan pendapatan minimal masyarakat di Kabupaten Bantaeng sebesar Rp.7.400.800/KK/tahun. Meskipun lebih kecil dari pendapatan minimal, namun pendapatan masyarakat Hutan Desa Pattaneteang dari dalam Hutan Desa apabila ditotalkan dengan pendapatan dari luar Hutan Desa akan memiliki nilai lebih besar yaitu Rp. 17.398.500/KK/tahun.

\subsection{Analisis Pendapatan dari Luar dan dari Dalam Hutan Desa}

Berdasarkan hasil pengolahan data diketahui bahwa pendapatan masyarakat Hutan Desa Pattaneteang dari luar Hutan Desa telah melampaui pendapatan minimal di Kabupaten Bantaeng, sedang pendapatan dari dalam Hutan Desa Pattaneteang masih lebih kecil dari pendapatan minimal masyarakat 
di Kabupaten Bantaeng. Perbandingan antara pendapatan pertanian dari luar Hutan Desa dan pendapatan pertanian dari dalam Hutan Desa dapat dilihat pada Tabel 4.

Tabel 4. Perbandingan Pendapatan Masyarakat Hutan Desa Pattaneteang.

\begin{tabular}{lrrr}
\hline No. & Jenis Pendapatan & Total Pendapatan (Rp/KK/tahun) & Persentase $(\%)$ \\
\hline 1. & Luar Hutan Desa & 14.060 .500 & 80 \\
\hline 2. & Dalam Hutan Desa & 3.338 .000 & 20 \\
\hline & Total & 17.398 .500 & 100
\end{tabular}

Sumber: Hasil pengolahan data kuesioner, 2016.

Berdasarkan Tabel 4. bahwa dari total pendapatan masyarakat di Desa Pattaneteang hanya $20 \%$ berasal dari dalam Hutan Desa sedangkan $80 \%$ berasal dari luar Hutan Desa Pattaneteang. Pendapatan dari luar Hutan Desa melalui pertanian Kopi dan Cengkeh telah melampaui pendapatan minimal di Kabupaten Bantaeng, sedangkan pendapatan dari dalam Hutan Desa menjadi tambahan pendapatan yang membuat kesejahteraan masyarakat Hutan Desa Pattaneteang lebih meningkat.

\subsection{Analisis Pengaruh Pendapatan pada Kelestarian Hutan Desa Pattaneteang}

\subsubsection{Pengaruh Pendapatan pada Lahan Kelola Masyarakat Hutan Desa Pattaneteang dari luar Hutan Desa}

Berdasarkan hasil perhitungan diketahui bahwa pendapatan Masyarakat Hutan Desa Pattaneteang dari luar Hutan Desa sebesar Rp. 14.060.500 KK/tahun. Pendapatan tersebut berasal dari hasil penjualan produksi tanaman Kopi sebesar Rp. 7.780.500 KK/tahun dan tanaman Cengkeh sebesar Rp. 6.280.000 KK/tahun. Pendapatan dari produksi tanaman Kopi dan tanaman Cengkeh apabila dibandingkan dengan pendapatan minimal masyarakat di Kabupaten Bantaeng, maka pendapatan dari lahan kelola masyarakat Hutan Desa Pattaneteang dari luar Hutan Desa sudah lebih besar dari pendapatan minimal dengan selisih Rp.6.659.700 KK/tahun.

Apabila pendapatan tersebut dijadikan dasar pertimbangan masyarakat untuk memenuhi kebutuhan, maka tidak perlu lagi masyarakat Hutan Desa Pattaneteang mencari pendapatan lain dengan melakukan pertanian di dalam Hutan Desa. Hal tersebut tentunya akan berpengaruh pada berkurang atau ditinggalkannya lahan kelola pertanian masyarakat di dalam Hutan Desa sehingga dengan sendirinya penutupan lahan hutan akan melakukan suksesi alami. Hasil dari suksesi alami akan merevegetasi kembali Hutan Desa Pattaneteang sehingga Hutan Desa Pattaneteang sebagai bagian dari hutan lindung akan kembali lestari.

Hasil riset ini tentunya akan menjadi konsep yang baik bagi kondisi Hutan Desa Pattaneteang, namun berdasarkan hasil pengamatan lapangan,wawancara dengan pihak terkait dan kajian pustaka maka terdapat beberapa tantangan apabila konsep tersebut diaplikasikan di lapangan. Pertama, pendapatan terbesar masyarakat Hutan Desa Pattaneteang dari Luar Hutan Desa adalah tanaman Cengkeh. Tanaman Cengkeh menjadi primadona karena memiliki harga yang tinggi di pasaran, namun apabila ditelisik lebih jauh tanaman Cengkeh adalah komoditi pertanian yang sering mengalami fluktuasi harga. Peningkatan harga Cengkeh terjadi pada tahun 2001 hingga mencapai Rp. 51.223/kg atau setara dengan harga saat data diambil pada tahun 2015 sebesar Rp.146.458/kg (www.simulasikredit.com). Harga Cengkeh pada tahun 2003 ditingkat produsen turun drastis menjadi Rp. 26.088/kg atau setara dengan harga saat data diambil pada tahun 2015 sebesar Rp. 60.232/kg. Harga Cengkeh bergerak fluktuatif pada tahun-tahun selanjutnya hingga pada tahun 2012 harga Cengkeh sebesar Rp. 57.577/kg atau setara dengan harga saat data diambil sebesar Rp. 70.526/kg (Pusat Data dan Informasi Pertanian, 2014). Saat riset ini dilakukan pada tahun 2015 , harga jual ditingkat masyarakat Hutan Desa Pattaneteang sebesar Rp. 140.000/kg atau setara dengan harga Rp. 87.067/kg pada tahun 2008 saat data pendapatan minimal diambil. Kondisi harga yang tidak menentu akan membuat masyarakat berpikir ulang 
meninggalkan lahan kelola pertanian di dalam Hutan Desa karena kondisi harga kopi yang diusahakan cenderung stabil di pasaran.

\subsubsection{Pengaruh Pendapatan pada Lahan Kelola Masyarakat Hutan Desa Pattaneteang dari dalam Hutan Desa}

Berdasarkan hasil signifikasi pengaruh pendapatan masyarakat Hutan Desa Pattaneteang dari dalam Hutan Desa Pattaneteang (X2) dengan lahan kelola dari dalam Hutan Desa Pattaneteang (Y2) dapat dilihat pada Tabel 5. Berdasarkan model tersebut diketahui bahwa nilai konstanta menunjukkan pengaruh positif pada variabel pendapatan masyarakat Hutan Desa Pattaneteang dari dalam Hutan Desa Pattaneteang. Apabila variabel pendapatan masyarakat Hutan Desa Pattaneteang naik atau berpengaruh dalam satuan, maka luas lahan kelola pertanian di dalam Hutan Desa akan bertambah.

Tabel 5. Analisis Signifikasi Pendapatan Masyarakat Hutan Desa Pattaneteang dari dalam Hutan Desa pada Lahan Kelola Hutan Desa Pattaneteang

\begin{tabular}{|c|c|c|c|}
\hline Model & Koefisien Regresi & t & Sig. \\
\hline (Constant) & 0,036 & 0,984 & 0,333 \\
\hline X2 & 0,54 & 6,500 & 0,000 \\
\hline \multicolumn{3}{|l}{} \\
\hline
\end{tabular}

Sumber: Hasil pengolahan data kuesioner, 2016

Berdasarkan Tabel 5., bahwa setiap kenaikan Pendapatan Masyarakat Hutan Desa Pattaneteang dari dalam Hutan Desa Pattaneteang (X2) sebesar Rp. 0,54 juta akan mengakibatkan bertambahnya lahan kelola dari dalam Hutan Desa Pattaneteang (Y2) seluas 0,036. Nilai t hitung adalah 6,50 dengan nilai signifikasi $0,000<0,05$ yang berarti adanya pengaruh pendapatan (X2) pada lahan kelola (Y2). Setiap pertambahan pendapatan sebesar Rp.1.000.000,-, maka lahan kelola akan bertambah seluas 0,576 ha. Berdasarkan Tabel 4.17, dapat diketahui persamaan dari Regresi Sederhana yaitu: $\mathrm{Y} 2=0,036+0,54 \mathrm{X} 2$

Persamaan tersebut bersifat positif, yang berarti setiap pertambahan $\mathrm{X} 2$ atau pendapatan di dalam Hutan Desa Pattaneteang, maka Y2 atau lahan kelola di dalam Hutan Desa Pattaneteang akan terus bertambah. Berdasarkan RKPHD Pattaneteang, telah ditetapkan luas lahan kelola maksimal yang dapat dimanfaatkan untuk pertanian di Hutan Desa Pattaneteang. Luas lahan kelola maksimal adalah 148 ha yang ditetapkan oleh Gubernur Sulawesi Selatan sebagai lampiran SK. Nomor: 3804/XI/TH/2010 tanggal 26 November 2010. Luasan tersebut akan menjadi batas bagi masyarakat Hutan Desa Pattaneteang untuk mendapatakan evaluasi pemerintah sebagai pemberi izin. Pemerintah dapat melakukan tindakan pencabutan izin atau hak penegelolaan apabila luas areal kelola lahan untuk tanaman Kopi bertambah dari luas yang telah ditentukan.

Pengujian persamaan yang telah didapatkan dilakukan untuk mengetahui seberapa besar pendapatan yang diperlukan untuk mencapai batas maksimal lahan kelola pemanfaatan oleh masyarakat Hutan Desa Pattaneteang. Berdasarkan hasil perhitungan, luas lahan kelola akan mencapai batas maksimalnya apabila pendapatan mencapai Rp. 275.000.000,-. Adapun hasil perhitungan dengan menggunaakan persamaan tersebut adalah sebagai berikut:

$\mathrm{Y} 2=0,036+0,54 \mathrm{X} 2$

$Y 2=0,036+0,54 \times 275.000 .000,-$

$Y 2=148,536$ ha 


\section{KESIMPULAN}

Pendapatan masyarakat Desa Pattaneteang lebih besar dari luar Hutan Desa Pattaneteang sebesar Rp. 14.060.500/KK/tahun sedangkan dari dalam Hutan Desa Pattaneteang sebesar Rp. 3.338.000/KK/tahun. Terdapat pengaruh pendapatan masyarakat Hutan Desa pada lahan kelola di dalam Hutan Desa Pattaneteang dimana, setiap pertambahan pendapatan sebesar Rp.1.000.000,-, maka lahan kelola akan bertambah seluas 0,576 ha. Pertambahan luas lahan kelola pertanian di dalam Hutan Desa akan berpengaruh pada kelestarian Hutan Desa Pattaneteang sebagai bagian dari hutan lindung, sehingga batas maksimal pengelolaan yang sudah disepakati harus mendapatkan kontrolberbagai pihak.

\section{UCAPAN TERIMA KASIH}

Berisi ucapan terima kasih kepada Keluarga Kecil penulis yang telah banyak diabaikan waktu kebersamaan selama menempuh perkuliahan, Direktur Penyiapan Kawasan Perhutanan Sosial Kementerian Lingkungan Hidup dan Kehutanan beserta jajarannya atas segala dukungannya.

\section{DAFTAR PUSTAKA}

Aji, BU, Suryanto, Joko, Yulianti, Rusida, Wirati, Amorisa, Abdurahhim, Yansyah A dan Miranda, TI. 2012. Laporan Penelitian: Strategi Pengurangan Kemiskinan Di Desa-Desa Sekitar hutan. Pusat Penelitian Kependudukan, Lembaga Ilmu Pengetahuan Indonesia, Jakarta.

Al Bornoz, et al , 2008. Menuju Kesejahteraan Dalam Masyarakat Hutan: Buku Panduan Untuk Pemerintah Daerah. CIFOR, Bogor.

Al Hasan R, Yumantoko. 2012. Kemiskinan Masyarakat Sekitar Hutan (Studi kasus di pulau Lombok). Prosiding seminar nasional. FISIP-UT.

Amafnini, P, 2012. Hutan Desa: Apa Tujuannya dan Bagaimana Pelaksanaannya? http://sancapapuana.wordpress.com/2012/04/08/hutan-desa-apa-tujuannya-dan-bagaimanapelaksanaannya-2/. 27 Desember 2014, pk. 22.48 WIB.

Awang, S.A.. 2010. Hutan Desa: Realitas tidak terbantahkan sebagai alternatif model pengelolaan hutan di Indonesia. Prosiding Seminar Hutan Desa: Alternatif Pengelolaan Hutan Berbasis Masyarakat. Yayasan DAMAR \& The Ford Foundation. Yogyakarta.

Cohen, L., Manion, L and Morrison, K., 2007. Research Methods In Education. Routledge Publishers (part of the Taylor \& Francis group), Oxford, UK.

Nagel, J.P.F., 2011. Pelestarian Hutan Dalam Hubungannya Dengan Lingkungan dan Potensi Ekonomi. Prosiding PESAT Universitas Gunadarma Volume 4 Tahun 2011. ISSN 1858-2559.

Silaen, AP, 2008. Pelestarian Fungsi Hutan Dan Lingkungan Hidup Dalam Perspektif Hukum Lingkungan. Jurnal Visi Universitas Nommensen Volume 16.

Soekartawi. 2006. Analisis usahatani. Penerbit Universitas Indonesia. UI Press Jakarta.

Subarna, Trisna. 2011. Faktor Yang Mempengaruhi Masyarakat Menggarap Lahan di Hutan Lindung: Studi Kasus di Kabupaten Garut Jawa Barat. JURNAL Penelitian Sosial dan Ekonomi Kehutanan Vol. 8 No. 4 Desember 2011.

Sugiyono. 2014. Metode Penelitian Kombinasi (Mixed Methods). CV. Penerbit Alfabeta, Bandung.

Sugiyono. 2009. Metode Penelitian Kuantitatif, Kualitatif, dan R \& D. Bandung (ID): CV. Penerbit Alfabeta.

Supratman dan Sahide, MAK, 2013. Hutan desa dan pembangunan sosial ekonomi masyarakat desa di Kabupaten Bantaeng. Direktorat Bina Perhutanan Sosial Kementerian Kehutanan dan Kemitraan Partnership. Jakarta. 